\title{
COVID-19 Outbreak in Post-Soviet States: Modeling the Best and Worst Possible Scenarios
}

\author{
Alpamys Issanov ${ }^{1+}(\mathbb{D})$, Yerlan Amanbek ${ }^{2 \dagger}(\mathbb{D})$, Anara Abbay ${ }^{1}(\mathbb{D})$, Shalkar Adambekov $^{3}(\mathbb{D})$, Mohamad Aljofan $^{4}(\mathbb{D})$ \\ Ardak Kashkynbayev ${ }^{2}$ (D), Abduzhappar Gaipov ${ }^{1^{*}}$ (D)
}

\author{
${ }^{1}$ Department of Clinical Sciences, Nazarbayev University School of Medicine, Nur-Sultan, KAZAKHSTAN \\ ${ }^{2}$ Department of Mathematics, Nazarbayev University School of Sciences and Humanities, Nur-Sultan, KAZAKHSTAN \\ ${ }^{3}$ Department of Epidemiology, University of Pittsburgh Graduate School of Public Health, Pittsburgh, PA, USA \\ ${ }^{4}$ Department of Biomedical Sciences, Nazarbayev University School of Medicine, Nur-Sultan, KAZAKHSTAN \\ : Alpamys Issanov and Yerlan Amanbek equally contributed as the first author \\ *Corresponding Author: abduzhappar.gaipov@nu.edu.kz
}

Citation: Issanov A, Amanbek Y, Abbay A, Adambekov S, Aljofan M, Kashkynbayev A, Gaipov A. COVID-19 Outbreak in Post-Soviet States: Modeling the Best and Worst Possible Scenarios. Electron J Gen Med. 2020;17(6):em256. https://doi.org/10.29333/ejgm/8346

ARTICLE INFO

Received: 10 May 2020

Accepted: 5 Jun. 2020

\begin{abstract}
Background: COVID-19 pandemic has presented extreme challenges to developing countries across the world. The aim of this paper was to provide estimates for current development COVID-19 pandemic in the Post-Soviet states and forecast potential best and worst scenarios for spread of this deadly infection.

Methods: The data on COVID-19 cases extracted from official governmental sources until April 18, 2020. A modified SEIR (Susceptible-Exposed-Infected-Recovered) modelling was used to plot the pandemic outbreak in 10 PostSoviet states and forecasting over the period of 10, 30 and 60 days. The optimal measures (best-scenario) and suboptimal measures (worst-scenarios) of potential spread of COVID-19 in these countries were estimated.

Results: It was estimated that Armenia and Azerbaijan have reached their peaks, Kazakhstan, Kyrgyzstan, Moldova, and Uzbekistan are expected to reach their peaks in the early May-2020), with comparatively low cases of COVID-19 in the best-case scenario. In contrast, Belarus, Russia, and Ukraine would likely see the outbreaks with the largest number of COVID-19 cases amongst the studied Post-Soviet States in the worst-scenario during the next 30 and 60 days.

Conclusion: Governmental response was shown to be as an important determining factor responsible for the development of COVID-19 epidemic in Post-Soviet states. The current protection rates should be maintained to reduce active cases during upcoming 30 and 60 days. The estimated possible scenarios based on the proposed model can potentially be used by healthcare professionals from each studied Post-Soviet States as well as others to improve plans to contain the current and future epidemic.
\end{abstract}

Keywords: SARS-COV-2, estimation model, Central Asia, Post-Soviet states, pandemic, scenarios

\section{INTRODUCTION}

The recent pandemic of acute respiratory tract infection caused by a novel strain of coronavirus first detected in Wuhan city, China, in December 2019 (1,2). The International Committee of Taxonomy of Viruses officially named the novel coronavirus as "Severe acute respiratory syndrome coronavirus 2 (SARS-CoV-2)"; and the World Health Organization (WHO) labelled the clinical syndromes caused by SARS-CoV-2 as Coronavirus disease (COVID-19) (3-5). The virus spreads rapidly across the globe affecting 215 countries and territories with over $6.7 \mathrm{M}$ confirmed cases and total $393 \mathrm{~K}$ confirmed deaths as of June 5th, 2020 (4). Europe (Italy, Spain, France, Germany), USA, UK, China and Iran have reported the highest incidence and mortality from COVID-19 leading to catastrophic health, economic and social repercussions (4). COVID-19 is expected to have even more severe impact on developing countries once the pandemic reaches its peak in regions with more vulnerable economies and health systems.

These include the healthcare systems in the Post-Soviet states, which are transitioning from the Soviet healthcare system, characterized by a centralized system of governance of hospitals, public health organizations, and health departments, to modernized healthcare systems adaptable to market economy (6). These include three developing countries in the Central Asia region and seven countries from Eastern European region, which for the best part of the 20th century, were part of the Soviet Union until their independence in the early 1990s. While these counties currently have different economic and political systems, most of these countries have similar healthcare systems and public health challenges inherited from Soviet Union (7). However, the transitioning seems to be slower than expected and that these systems remain somewhat unchanged from the Soviet era, highlighting the need for rapid improvement of resources and patient access. 
Following the confirmation of the first of COVID-19 cases in a part of Europe, most of the Post-Soviet states took various pathways in introducing and tightening preventive measures of COVID-19 outbreaks, such as limiting or suspending all public transportation, cancelling of public events, restricting people from leaving their residence, and complete lockdown of cities (8-13). An outbreak predicting system is an extremely useful and vital tool of preparedness of such events. The majority of these systems utilizes available data and applies mathematical and/or statistical modeling capable of predicting a future outbreak (14-16). There were several attempts in different countries to establish a modelling method for the prediction of COVID-19 spread including a group in China which estimated the serial interval for COVID-19 (17), to predict the dynamics of COVID-19 spread $(18,19)$. Applying a mathematical model on the available data, a group showed that lockdown measures were effective in reducing COVID-19 transmission rate and that imported cases have a different dynamic of transmission. Similarly, using an agestructured compartmental model of COVID-19 transmission, a Canadian group showed that significant strengthening of quarantine measures could prevent extreme overloading of intensive care unit (ICU) resources (20). However, the situation in the Post-Soviet countries remains uninvestigated.

To date, each the Post-Soviet countries initiated their own preventive actions against the spread of COVID-19, which led to high healthcare expenditures and economic slow-down (13). The high economic, social and health impacts of the pandemic make it hard to determine how long each of these developing countries would be able to maintain the strict measures. Therefore, there is a need for a reliable prediction model for these countries, to determine the status of preparedness. A system capable of determining whether governmental preparedness policies are maintained, and the spread is stopped/slowed as a best-case scenario; or policies not maintained and thus disease spread continuously unabated, worst case scenario. Such models are important to provide the projected estimates that can be used by governments and public health practitioners who are responsible for responding to COVID-19 epidemic.

Therefore, the aim of this study was to provide a reliable mathematical model capable of determining the best- and worst-case scenarios for the development of COVID-19 epidemic in the Post-Soviet States, considering the effects of optimal and suboptimal measures, respectively. The model is based on a modified version of the Susceptible-ExposedInfectious-Recovered (SEIR) deterministic mathematical model. We will also discuss how the measures taken by each country are affecting the current situation in Post-Soviet States, as well as providing a predictive scenario of the bestand worst-cases for this highly vulnerable region in comparison with other Post-Soviet States.

\section{METHODS}

\section{Data Collection}

Data on country-specific population size, population density and percentage of population 65 years or over were extracted from the United Nations (UN) official website $(21,22)$. Health expenditure and country ranking data were collected from the World Bank databases (23). The number of air passengers carried in both domestic and international flights for each country were obtained from the International Civil Aviation Organization, except Armenia whose data was collected from the International Air Transport Association $(24,25)$.

The total daily data of newly confirmed COVID-19 infected, recovered cases and number of COVID-19 deaths in selected Post-Soviet States in the region were obtained from the official websites of the Ministries of Health in each of the studied countries including Armenia, Azerbaijan, Belarus, Georgia, Kazakhstan, Kyrgyzstan, Moldova, Russia, Ukraine, and Uzbekistan (13). The daily data were collected from a date of first 5-20 confirmed cases in each country until April 18, 2020. Given the absence of COVID-19 infected cases, Tajikistan and Turkmenistan were excluded from the study. Also, Baltic states (Estonia, Latvia and Lithuania) were excluded due to the difference in their health care systems, policy implementation and economic situation to that of the Post-Soviet States. Of note, the included COVID-19 cases were laboratory confirmed using WHO guidelines (26) while recovered cases were defined as "those that were previously tested positive to COVID-19 (laboratory confirmed) and later had negative test results". While some of the studied countries introduced serological testing to investigate retrospective outbreaks by identifying asymptomatic immunized people, they were excluded in the current mathematical model of forecasting.

\section{Mathematical Modeling Method}

The two most common deterministic models used in the literature are the logistic and modified Susceptible-InfectiousRecovered (SIR) models $(15,18)$. Although the logistic model requires less data, it underestimates peak timing and the number of cases (27). Instead, a modified SEIR model "Susceptible-Protected-Exposed-Infectious-Quarantined-

Recovered-Dead" (SPEIQRD) was used (28). This SPEIQRD framework incorporates additional public health interventions such as, self-isolation of exposed, quarantine of infectious and isolation of susceptible. Parameters describing the natural history and clinical path of COVID-19 were derived from published literature. An overview of the SPEIQRD framework, its compartments and movements between them can be found in Figure 1. More information about each compartment can be found in Supplementary data (Appendix 1, Model 1). The forecasting model was performed to cover a period of 10,30 and 60 days from June 5, 2020, and it was assumed that recovered people remain immune from reinfection for the duration of the pandemic. The model assumes that individuals remained infectious until they recovered, quarantined, or died and that all confirmed cases would have been quarantined. In the worst case scenario, it was assumed that the rate of movement from susceptible to protected (protection rate, alpha) will decrease by $50 \%$, whereas in the best case scenario, the protection rate increases by $20 \%$ as suggested by the literature (20). The model was performed in Matlab 19a version (The MathWorks, Inc., Natick, MA 01760, USA).

\section{Numerical Simulations}

For the numerical simulations, we ignored the birth and natural death rates since they have insignificant effect compared to other parameters such as the high transmission rate of COVID-19. That is, we set $\Lambda=0$ and $\mu=0$ and we modify the model as follows in (Model 2), which was proposed by Peng, et al (2020) (1). We have estimated parameters by fitting to available COVID-19 data from the official websites of Ministry of 


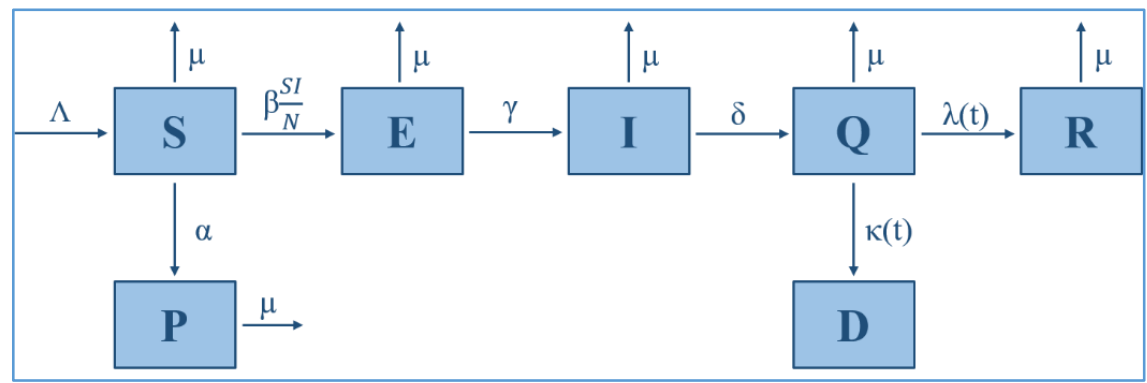

Figure 1. Algorithm of SPEIQRD model

Table 1. Country profiles and parameters are provided in the fitted model for each country

\begin{tabular}{|c|c|c|c|c|c|c|c|c|}
\hline Country & $\begin{array}{l}\text { Population } \\
\text { (2019), mln }\end{array}$ & $\begin{array}{c}\text { Population } \\
\text { density } \\
\text { person/km² } \\
\text { (2019) }\end{array}$ & $\begin{array}{c}\% \text { of } \\
\text { population } 65 \\
\text { years or over } \\
(2019)\end{array}$ & $\begin{array}{c}\text { Current health } \\
\text { expenditure } \\
\text { per capita } \\
\text { (current US\$, } \\
\text { 2017) } \\
\end{array}$ & $\begin{array}{c}\text { Total } \\
\text { expenditure on } \\
\text { health as } \% \text { of } \\
\text { GDP (2017) }\end{array}$ & $\begin{array}{l}\text { Air passengers } \\
\text { (2018), mln }\end{array}$ & $\begin{array}{c}\text { Air passengers } \\
\text { per capita } \\
(2018)\end{array}$ & $\begin{array}{l}\text { World } \\
\text { bank } \\
\text { rank }^{\star}\end{array}$ \\
\hline Armenia & 2.9 & 104 & 11 & 407.6 & 10.4 & 2.83 & 0.98 & UMIC \\
\hline Azerbaijan & 10.0 & 122 & 6 & 275.8 & 6.6 & 2.28 & 0.23 & UMIC \\
\hline Belarus & 9.4 & 47 & 15 & 342.5 & 5.9 & 2.76 & 0.29 & UMIC \\
\hline Georgia & 4.0 & 58 & 15 & 293.0 & 7.6 & 0.52 & 0.13 & UMIC \\
\hline Russia & 145.9 & 9 & 15 & 585.9 & 5.3 & 99.33 & 0.68 & UMIC \\
\hline Kazakhstan & 18.5 & 7 & 8 & 279.6 & 3.1 & 7.14 & 0.39 & UMIC \\
\hline Kyrgyzstan & 6.4 & 33 & 5 & 78.8 & 6.2 & 0.71 & 0.11 & LMIC \\
\hline Moldova & 4.0 & 123 & 12 & 191.2 & 7.0 & 1.14 & 0.29 & LMIC \\
\hline Ukraine & 44.0 & 76 & 17 & 177.4 & 7.0 & 7.85 & 0.18 & LMIC \\
\hline Uzbekistan & 33.0 & 78 & 5 & 98.8 & 6.4 & 3.06 & 0.09 & LMIC \\
\hline
\end{tabular}

*World bank classifies country economies into four groups: high income country (HIC), upper-middle income country (UMIC), lower-middle income country (LMIC) and low income (LIC).

Country income is calculated as gross national income (GNI) per capita, in US\$ (23).

Health in each country. The function for the fitting is Matlab's function Isqcurvefit (29) and the code was derived from E. Cheynet et al. (30). Modified SPIERQD Model 2 presented in following equations:

$$
\begin{aligned}
& \frac{d S}{d t}=-\alpha S(t)-\beta \frac{S(t) I(t)}{N}, \\
& \frac{d P}{d t}=\alpha S(t), \\
& \frac{d E}{d t}=-\gamma E(t)+\beta \frac{S(t) I(t)}{N}, \\
& \frac{d I}{d t}=-\delta I(t)+\gamma E(t), \\
& \frac{d Q}{d t}=-(\lambda(t)+\kappa(t)) Q(t)+\delta I(t), \\
& \frac{d R}{d t}=\lambda(t) Q(t), \\
& \frac{d D}{d t}=\kappa(t) Q(t),
\end{aligned}
$$

One can easily see that for the modified model the basic reproduction number simplifies to

$$
\mathrm{R}_{0}=\frac{\beta(1-\alpha)^{t}}{\delta}
$$

where t represents number of days.

Based on above calculations, the reproduction number $\left(R_{0}\right)$ for each country was generated and presented in Supplementary Table 1 as well as dynamical changes of $R_{0}$ over the time depicted in Supplementary Figure 1.

\section{RESULTS}

\section{Country Specific Information and Healthcare Expenditure Data}

General country specific profiles of Post-Soviet States regarding the current population density and size with proportion of population aged $\geq 65$ years old, total expenditure on health per capita and percent of GDP, number of air passengers as well as world banking rank based on country income are presented in Table 1. Russia, Belarus, Kazakhstan, Azerbaijan, and Ukraine have total expenditures on health per capita more than $\$ 250$ and ranked as upper middle-income countries along with Armenia and Georgia. Countries including Belarus, Georgia, Russia and Ukraine have more than $15 \%$ of their populations aged $\geq 65$ years old.

\section{COVID-19 Outbreak Timeline and Taken State Preventive Measures}

Outbreak dates with implementation of preventive measures by country are presented in Table 2 . Russia reported the first confirmed case of COVID-19 infection (January 31, 2020), which was earlier than other Post-Soviet States. At the end of February 2020, Azerbaijan, Belarus, Georgia, Armenia and Ukraine declared the first positive cases in their territories. Kazakhstan, Uzbekistan and Kyrgyzstan reported their first cases approximately two weeks later. Prior to introducing a state emergency and imposing lockdowns, countries implemented similar measures to prevent spread of COVID-19 by limiting air travels to countries affected by the pandemic, closure of educational institutions and banning all mass gathering events (Table 2). Kazakhstan, Kyrgyzstan, Uzbekistan and Moldova were quick to introduce state emergency and closed their borders, whereas the Russian Federation waited significantly longer (two months after the first confirmed case). On the other hand, Belarus, as for April 18,2020 , has not yet imposed any preventative measures such as a state emergency, or national lockdown to prevent further spread of COVID-19. 
Table 2. Important outbreak dates and implement preventive measures by country

\begin{tabular}{|c|c|c|c|c|}
\hline Country & $\begin{array}{c}\text { Date of first } \\
\text { confirmed case } \\
\text { in country } \\
(2020)\end{array}$ & $\begin{array}{c}\text { Days after } \\
\text { first } \\
\text { confirmed } \\
\text { case in China }\end{array}$ & Actions taken prior declaration of state emergency & $\begin{array}{c}\text { State emergency } \\
\text { introduced days } \\
\text { after first confirmed } \\
\text { case in country }\end{array}$ \\
\hline Armenia & $1 \mathrm{Mar}$ & 54 & Prohibited entrance of citizens from countries affected by the pandemic & 15 \\
\hline Azerbaijan & 28 Feb & 52 & $\begin{array}{l}\text { Closure of borders, of educational institutions, suspension of all mass } \\
\text { gathering events }\end{array}$ & 32 \\
\hline Belarus & $28 \mathrm{Feb}$ & 52 & $\begin{array}{l}\text { Self-quarantine for } 14 \text { days after arrival, the spring vacation was } \\
\text { extended in schools }\end{array}$ & not yet \\
\hline Georgia & 26 Feb & 50 & $\begin{array}{l}\text { Screening people travelling from abroad and limiting air connections, } \\
\text { prohibited entrance of foreign nationals and closure of educational } \\
\text { institutions. }\end{array}$ & 24 \\
\hline Russia & 31 Jan & 24 & $\begin{array}{l}\text { Restricting the border with countries affected by the pandemic and } \\
\text { limiting air connections }\end{array}$ & 59 \\
\hline Kazakhstan & $13 \mathrm{Mar}$ & 66 & Screening people travelling from abroad and limiting air connections, & 3 \\
\hline Kyrgyzstan & $18 \mathrm{Mar}$ & 71 & All borders to foreigners were closed on Mar 18 & 4 \\
\hline Moldova & $7 \mathrm{Mar}$ & 60 & Closure of all kindergartens, schools, colleges and universities & 10 \\
\hline Ukraine & $3 \mathrm{Mar}$ & 56 & $\begin{array}{l}\text { Limiting air travelling to epidemic places, closure of educational } \\
\text { institutions, banning gatherings of over } 200 \text { people and cancelling flights } \\
\text { to countries with unfavorable epidemic situations }\end{array}$ & 22 \\
\hline Uzbekistan & $15 \mathrm{Mar}$ & 68 & $\begin{array}{l}\text { Limiting air connections with countries most affected by the pandemic, } \\
\text { closure of entertainment venues and banning large weddings and other } \\
\text { mass gatherings }\end{array}$ & 8 \\
\hline
\end{tabular}

\section{Mathematical Modeling of COVID-19 Outbreak}

The mathematical modeling of COVID-19 including current number of confirmed, recovered and deceased cases as well as their forecasting for 10 days presented in Figure 2. The model predicted that the number of active new cases would be decreasing during the upcoming week in Armenia only. On the other hand, it is estimated that Kazakhstan, Kyrgyzstan, Azerbaijan and Moldova are likely to reach the epidemic peak in the upcoming weeks. Uzbekistan, Russia, Belarus, Georgia and Ukraine have the steepest increase in the number of cases and are expected to continuously increase in the next 10 days.

Based on the forecasting modelling for 30 days (Figure 3), similar trends expected for Kyrgyzstan, Armenia, Azerbaijan, Kazakhstan and Moldova with maximum number of approximately $650,800,1,000,2,100$, and 2,500 active cases (except recovered and death cases) respectively, during the peak of the worst-case scenario. In the same case scenario, the
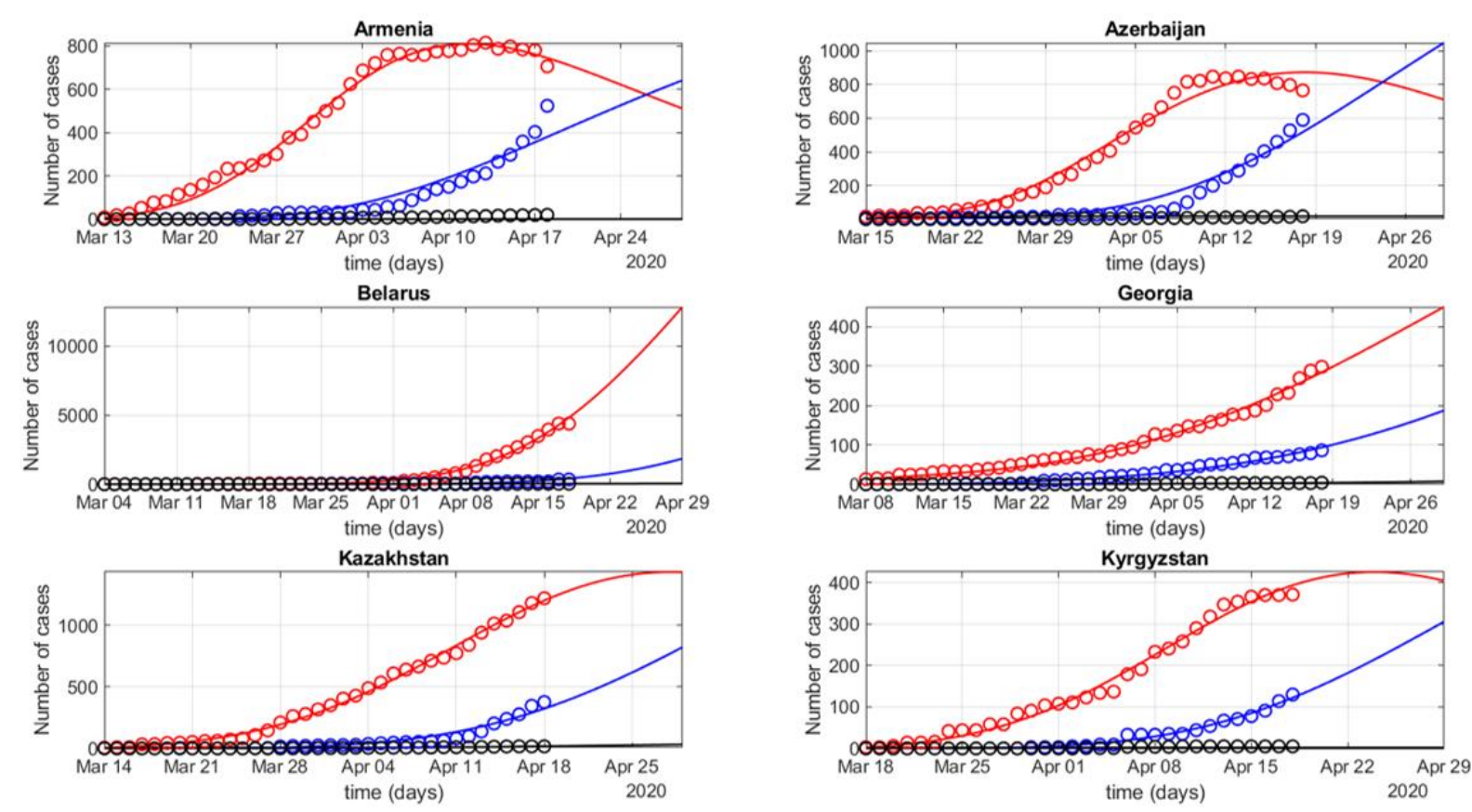

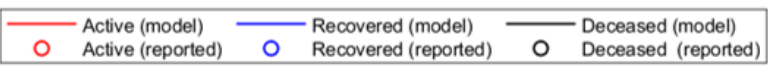

Figure 2. Modeling of COVID-19 outbreak prediction for 10 days

Note: Active (model) - mathematical modeling of active cases, which are all confirmed cases, excluding recovered and died; Active (reported) laboratory confirmed active cases, which are all confirmed cases, excluding recovered and died, over time based on reported data; Recovered (model) - mathematical modeling of recovered cases; Recovered (reported) - recovered cases over time based on reported data; Deceased (model) - mathematical modeling of COVID-19 deaths; Deceased (reported) - number of deaths over time based on reported data. 


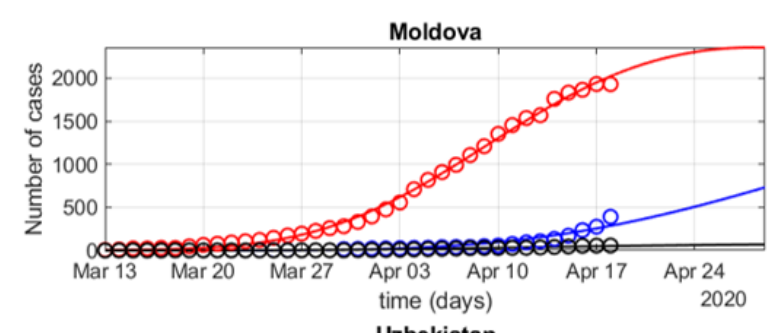

Uzbekistan

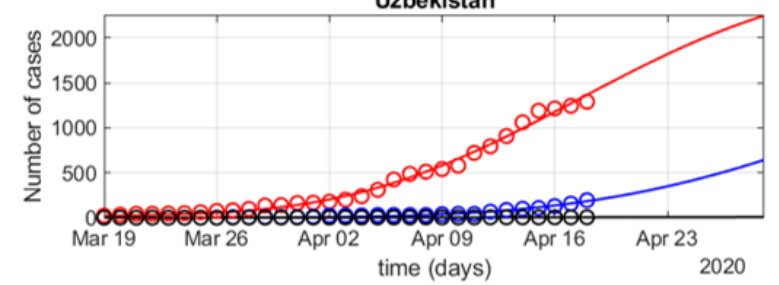

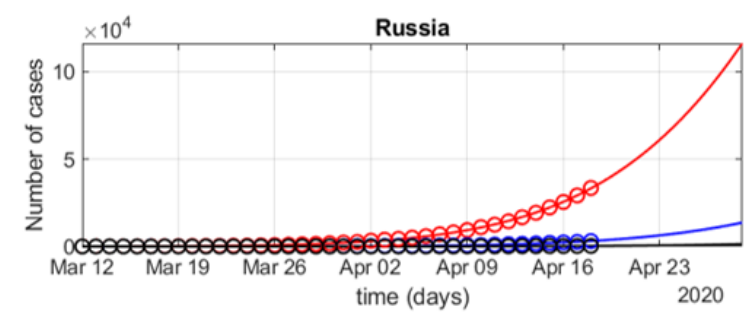

Ukraine

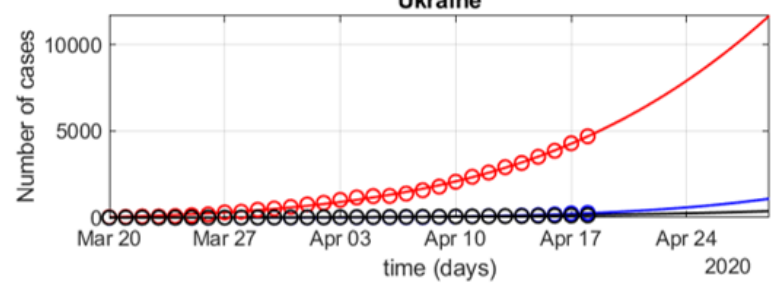

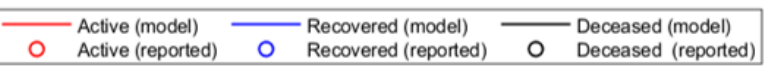

Figure 2 (continued). Modeling of COVID-19 outbreak prediction for 10 days

Note: Active (model) - mathematical modeling of active cases, which are all confirmed cases, excluding recovered and died; Active (reported) laboratory confirmed active cases, which are all confirmed cases, excluding recovered and died, over time based on reported data; Recovered (model) - mathematical modeling of recovered cases; Recovered (reported) - recovered cases over time based on reported data; Deceased (model) - mathematical modeling of COVID-19 deaths; Deceased (reported) - number of deaths over time based on reported data.
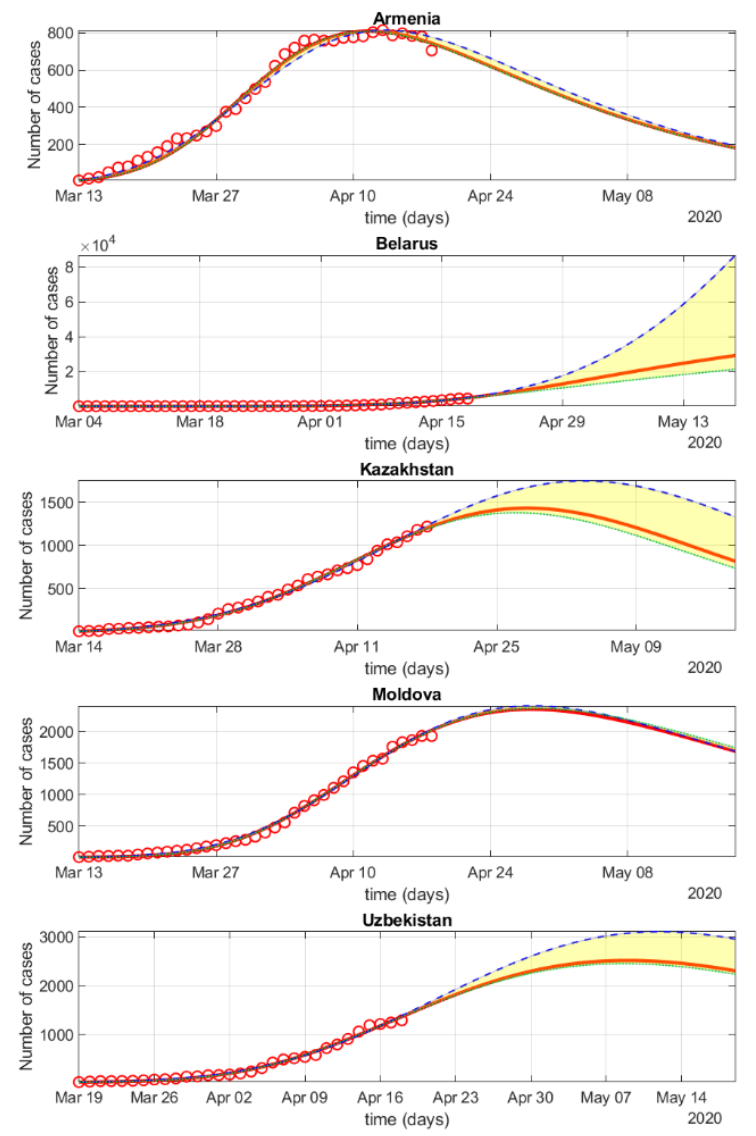
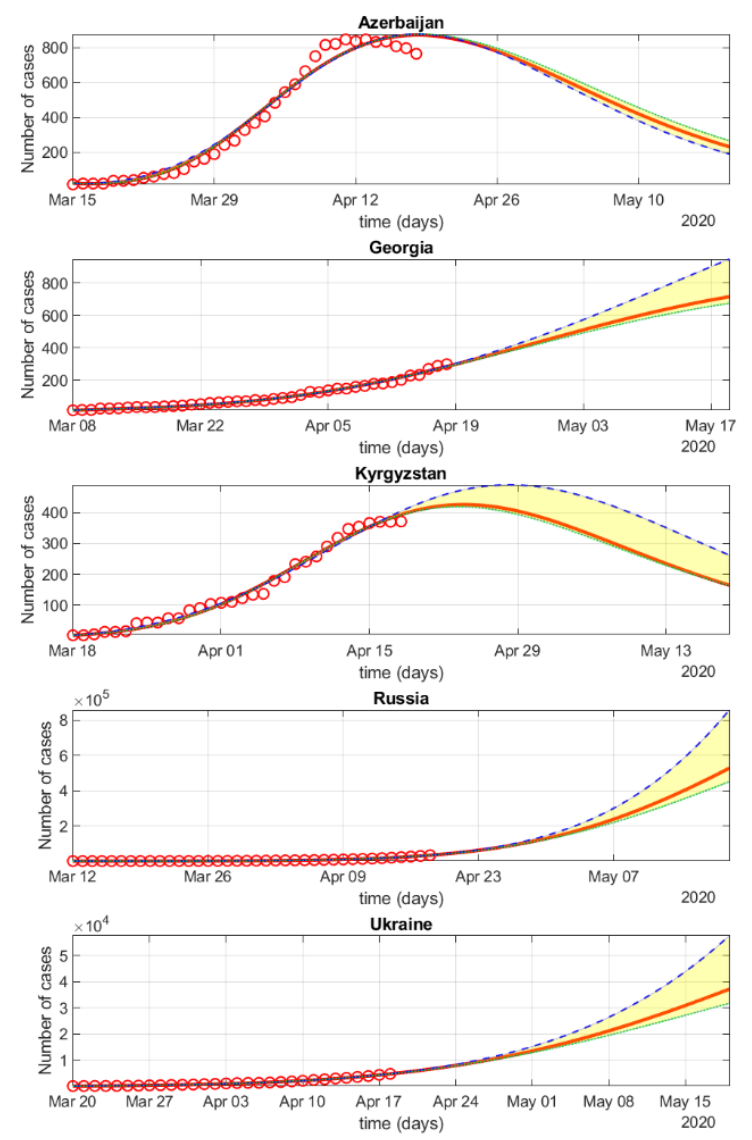

Figure 3. Better and worse spread scenarios of COVID-19 outbreak for 30 days

Note: Active (model) - mathematical modeling of active cases, which are all confirmed cases, excluding recovered and died; Active (reported) laboratory confirmed active cases, which are all confirmed cases, excluding recovered and died, over time based on reported data; Active (a worse) - mathematical modeling of active cases over time for the possible worst case scenario, in which protection rate was decreased by $50 \%$; Active $(\alpha$ better) - mathematical projection of active cases over time for the possible best-case scenario, protection rate was increased by $20 \%$; range - an interval which includes all possible active cases between the worst- and best-case scenarios. 

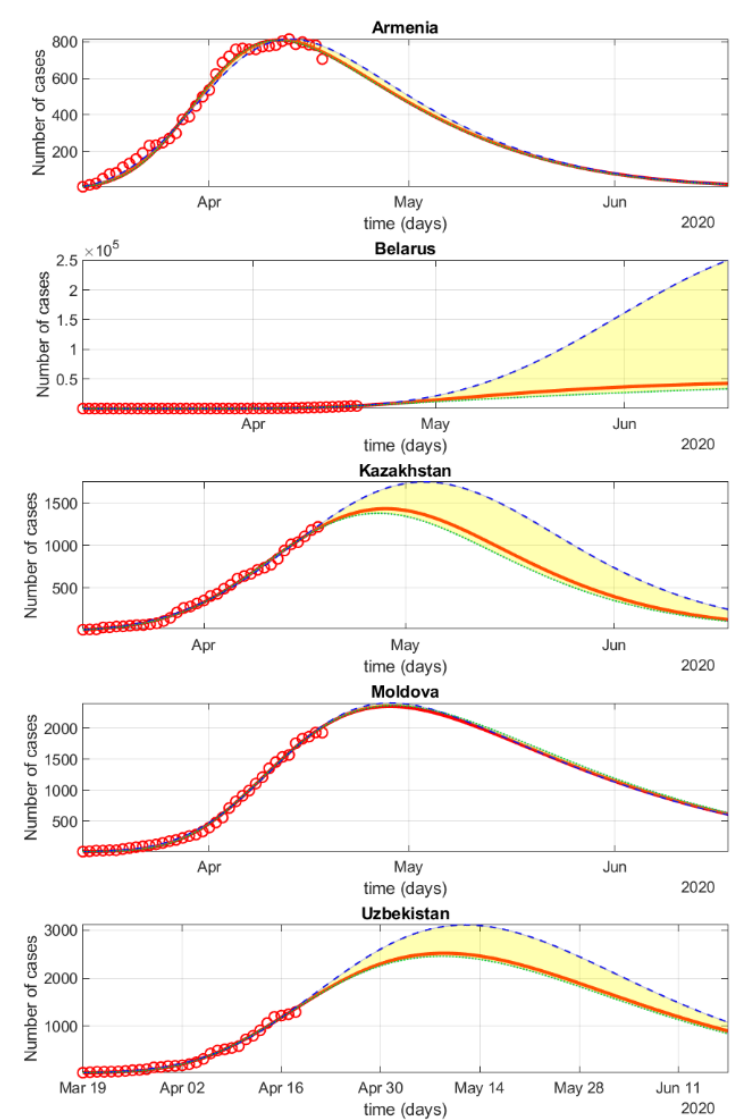
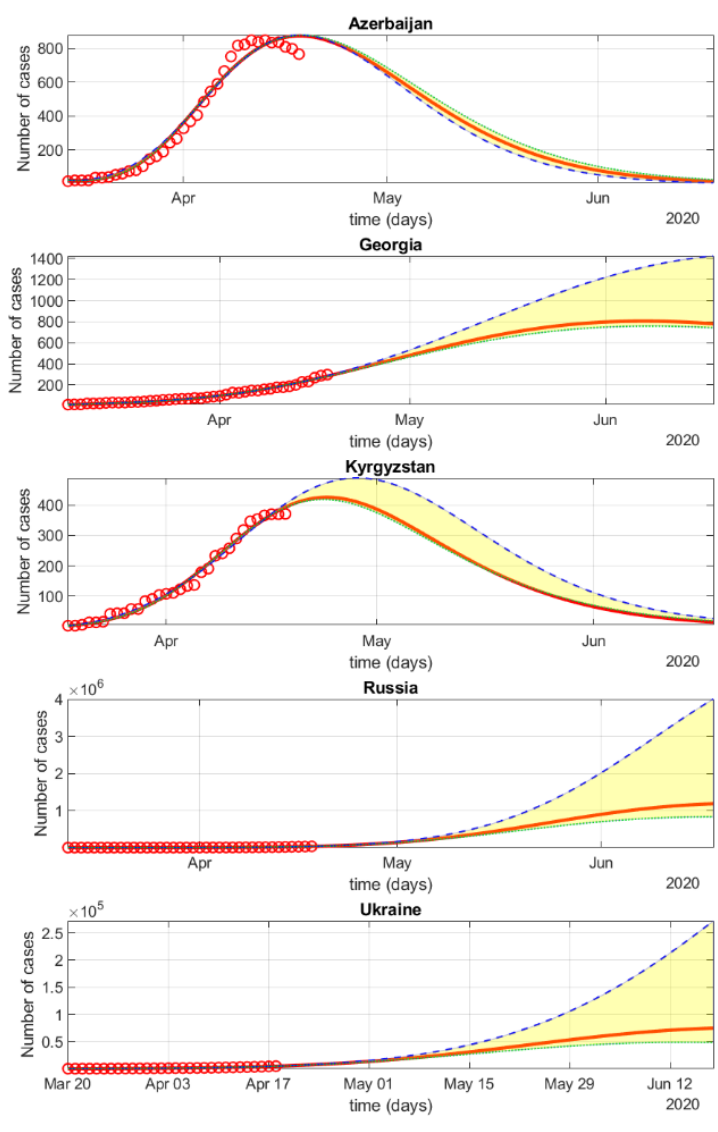

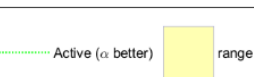

Figure 4. Better and worse spread scenarios of COVID-19 outbreak for 60 days

Note: Active (model) - mathematical modeling of active cases, which are all confirmed cases, excluding recovered and died; Active (reported) laboratory confirmed active cases, which are all confirmed cases, excluding recovered and died, over time based on reported data; Active (a worse) - mathematical modeling of active cases over time for the possible worst case scenario, in which protection rate was decreased by $50 \%$; Active ( $\alpha$ better) - mathematical projection of active cases over time for the possible best-case scenario, protection rate was increased by $20 \%$; range - an interval which includes all possible active cases between the worst- and best-case scenarios

rest of the countries would not reach the peak until mid-May with maximum numbers reaching approximately $700,5,000$, 53,000 144,000 and 800,000 active cases (except recovered and death cases) for Georgia, Uzbekistan, Ukraine, Belarus, and Russia, respectively.

Increasing the protection rate for Belarus, Russia, and Ukraine would likely have significantly effects on the overall curve of active cases (Figure 3 ). The countries that were predicted to expect the most significant decrease due to strengthening of quarantine measures were Belarus and Russia.

Based on the projection for 60 days of the worst-case scenario, Russia, Belarus, and Ukraine were shown to be at risk of prolongation of the epidemic peak until mid-summer and number of active cases could be tremendously large (Figure 4). Armenia, Azerbaijan, and Moldova are expecting to see a decreasing trend and stabilization of the epidemic, as increasing the protection rate would reduce the number of active cases and delay the epidemic peak for these countries. Kazakhstan, Kyrgyzstan, and Uzbekistan seem to be expecting decreasing trend of active cases by the end of 60 days, in the case of maintaining the current protection rate at same level. Belarus, Russia, and Ukraine could benefit from tightening quarantine measures (increasing the protection) in the coming 60 days, which would substantially decrease the number of active cases after peak, while Armenia, Azerbaijan, Georgia, Kazakhstan, Kyrgyzstan, Moldova and Uzbekistan are unlikely to benefit from any further increase in the protection rate.

Based on current modeling approach the approximate total number of COVID-19 infected patients in both best- and worst-case scenarios from the April 18, 2020 until forthcoming 30 days and 60 days, are presented in Supplementary Table 2.

\section{DISCUSSION}

In the current study we discuss the results of the deterministic mathematical modeling of spread of COVID-19 in the post-Soviet countries using existing data and the potential of best- and worst-case scenarios for the pandemic in each country individually. It was estimated that $R_{0}$ value is steeply decreasing in all countries suggesting that the governments have implemented more stringent measures to prevent the spread of COVID-19. The estimated $R_{0}$ for Belarus was the highest out of all other countries highlighting the Belarusian government's reluctance to take stricter actions to battle COVID-19 outbreak. On the other hand, Kazakhstan, and Armenia were showing promising $R_{0}$ values less than $<1$ indicating a potential reduction in transmissibility in the upcoming weeks. However, due to insufficient data in early 
stages of the outbreaks, estimated $R_{0}$ values should be recalibrated for Belarus as it might not accurately predict the future dynamics of COVID-19.

Despite the relatively similar dates of the first confirmed cases across the post-Soviet countries (13), the predictions for COVID-19 outbreak dynamics in each country were significantly different. For instance, Armenia, Moldova, Georgia, Uzbekistan, Kyrgyzstan, Azerbaijan, and Kazakhstan, would likely have relatively a smaller number of cases than Russia, Ukraine, and Belarus, suggesting the success of the early governmental imposed prevention measures.

It should also be noticed that the timeline of the outbreaks is associated with proximity to the epidemic of European countries (31). The Central Asian countries (Kazakhstan, Kyrgyzstan and Uzbekistan) have faced the outbreaks later and almost at the same time and were quick to implement national preventive measures. Geographical remoteness and low air travelling from the epidemic European countries to the Central Asian countries could have delayed epidemic introduction and allowed them to learn and act more effectively than others (24, 25). On the other hand, the significantly large expected numbers of COVID-19 cases in Belarus, Ukraine and Russia could put a substantial burden on the healthcare systems in these countries. Given the comparatively larger percentage of population older than 65 years old in these countries, it could be anticipated that older individuals with COVID-19 would overwhelm ICU capacity in all hospitals in the major cities which may lead to high mortality (20). Considering low total expenditure on health as percentage of GDP and reluctance from the Belarusian government to implement similar stringent preventive measures, the state could be in a disastrous situation where all healthcare resources could be exhausted to treat the unbearably large number of severe cases (23).

Containment of epidemics in inherently weak health care systems of the Post-Soviet States could be quite a challenging task to deal with. Despite the seemingly successful containment efforts in some countries, there is a possibility of repeated epidemics after loosening quarantine measures since a large proportion of the population will be susceptible to COVID-19 or until an effective prophylaxis or post infection treatment is developed and manufactured at population scale.

Post-Soviet States have considered the economic situation and preparedness of their healthcare systems in handling the current epidemic, and consequently have taken similar and stringent actions to prevent the spread, except Belarus $(6,7)$. The results of current modeling show that Armenia, Azerbaijan, Georgia, Kazakhstan, Kyrgyzstan, Moldova and Uzbekistan have taken effective preventive actions against the COVID-19 spread. However, Belarus with a weak economy and unwillingness to slow down the economy could be facing extreme consequences from potential collapse of their healthcare system as well as to possibly become one of the states with the largest number of COVID-19 casualties. Ukraine and Russia were slow in placing preventive actions from the beginning of the outbreak, and without abiding stringent actions they could be facing extreme number of cases comparable to some Western European countries. The Central Asian countries will most likely fortunate in avoiding major catastrophe with the current outbreak of COVID-19, which is partly due to their early preparation for the outbreak as well as their geographical remoteness and access for international travel which played a role in relatively delayed first cases in these countries.

\section{Limitations}

There are several limitations in this study. First, there could be some inaccuracies between reported data and what are the actual numbers are due to limited testing, reporting, and the potential unreported number of asymptomatic virus infected individuals $(32,33)$. This, however, is a common limitation given the novelty of the virus and limited access to testing in the majority of countries. The second limitation is that some countries have implemented certain policies that limit the reporting of incidence of COVID-19, and therefore, we cannot provide predictions for Turkmenistan and Tajikistan. The third limitation is that the current burden of COVID-19 is comparatively in the early stages of development and somewhat insignificant in some post-Soviet countries, which makes our projections less robust. The fourth limitation is that we do not take into account the spread within a specific country (regional, geographical), since we considered countries as entities, and individuals are not considered. For instance, in Kazakhstan, first cases and the majority of cases were reported in densely populated major cities (Almaty and Nur-Sultan), while the outbreak reached other less populated cities a week later. The further limitation is that the modeling is not stratified by age; thus, we could not estimate the number of cases of whom would likely to require ICU treatment. Another limitation is that we do not consider how each of preventive measures (e.g. wearing masks, physical distancing, hand washing) plays role in the protection rate and dynamics of the spread within healthcare settings. In addition, mathematical models have a common limitation; they might inaccurately predict future realistic data due to insufficient data for some countries.

Nonetheless, given the limitations, we attempted to provide insights into the future possible scenarios for policy makers and decision makers about the importance of timely actions and the possible consequences of relaxing the implemented measures. The estimated possible scenarios based on the proposed model can potentially be used by healthcare professionals from each studied Post-Soviet States as well as others to improve plans to contain the current and future epidemic.

\section{Conclusions}

Government responses were shown to be the major single factor in determining the rate of development of the COVID-19 epidemic in Post-Soviet States. Our model shows that the implementation of strict preventative measures can substantially reduce the spread of COVID-19 and that the premature loosening of these measures, in the worst-case scenario, could lead to a dramatically increase in the number of active cases and a possible prolongation of the epidemic. Based on the current confirmed cases, our model suggested that Russia, Belarus, and Ukraine would have higher cases than other Post-Soviet countries if preventive actions were to be relaxed.

\section{ACKNOWLEDGEMENT}

YA would like to acknowledge support of the FDCRG (Nazarbayev University), No 110119FD4502, the research grant, 
No AP08052762, from the Ministry of Education and Science of the Republic of Kazakhstan and the SPG (Nazarbayev University). AK was supported in part by Nazarbayev University FDCRG N 090118FD5353. AG acknowledge the funding from the Nazarbayev University Collaborative Research Program (CRP) for 2020-2022 (Funder Project Reference: 091019CRP2105) and Faculty Development Research Grant Program FDCRGP 20202022 (Funder Project Reference: 240919FD3913).

\section{REFERENCES}

1. Surveillances V. The epidemiological characteristics of an outbreak of 2019 novel coronavirus diseases (COVID-19)China, 2020. China CDC Weekly. 2020;2(8):113-22. https://doi.org/10.46234/ccdcw2020.032

2. Aljofan M, Gaipov A. COVID-19 Treatment: The Race Against Time. Electron J Gen Med. 2020;17(6):em227. https://doi.org/10.29333/ejgm/7890

3. World Health Organization (WHO). World Health Organization. Report of the WHO-China Joint Mission on Coronavirus Disease 2019 (COVID-19). 2020. Available at: https://www.who.int/docs/default-source/coronaviruse/ who-china-joint-mission-on-covid-19-final-report.pdf (Accessed: 17 April 2020).

4. Worldmeter. Coronavirus Cases_ Statistics and Charts Worldometer 2020. Available at: https://www.worldo meters.info/coronavirus/ (Accessed: 17 April 2020).

5. Lai C-C, Shih T-P, Ko W-C, Tang H-J, Hsueh P-R. Severe acute respiratory syndrome coronavirus 2 (SARS-CoV-2) and corona virus disease-2019 (COVID-19): the epidemic and the challenges. International journal of antimicrobial agents. 2020:105924. https://doi.org/10.1016/j.ijantimicag. 2020.105924 PMid:32081636 PMCid:PMC7127800

6. Rechel B, Richardson E, McKee M. Trends in health systems in the former Soviet countries. 2014. https://doi.org/ 10.1093/eurpub/cku162.088

7. Adambekov S, Kaiyrlykyzy A, Igissinov N, Linkov F. Health challenges in Kazakhstan and Central Asia. J Epidemiol Community Health. 2016;70(1):104-8. https://doi.org/ 10.1136/jech-2015-206251 PMid:26254293

8. Zhalmagambetov B, Madikenova M, Paizullayeva S, Abbay A, Gaipov A. COVID-19 Outbreak in Kazakhstan: Current Status and Challenges. Journal of Clinical Medicine of Kazakhstan. 2020;1(55):6-8. https://doi.org/10.23950/18122892-JCMK-00763

9. Sukhankin S. COVID-19 As a Tool of Information Confrontation: Russia's Approach. The School of Public Policy Publications. 2020;13.

10. Dyner AM. Economic Challenges for Belarus. 2020.

11. Nesteruk I. Long-term predictions for COVID-19 pandemic dynamics in Ukraine, Austria and Italy. medRxiv. 2020. https://doi.org/10.1101/2020.04.08.20058123

12. Analytica O. COVID-19 rises inexorably in Russia and neighbours. Emerald Expert Briefings. (oxan-ga).

13. WHO. World Health Organization: Coronavirus disease 2019 (COVID-19): situation report - 88. 2020. Available at: https://reliefweb.int/report/world/coronavirus-disease2019-covid-19-situation-report-88-17-april-2020 (Accessed: 17 April 2020).
14. Kucharski AJ, Russell TW, Diamond C, Liu Y, Edmunds J, Funk S, et al. Early dynamics of transmission and control of COVID-19: a mathematical modelling study. The lancet infectious diseases. 2020. https://doi.org/10.1101/ 2020.01.31.20019901

15. Cakir Z, Savas H. A Mathematical Modelling Approach in the Spread of the Novel 2019 Coronavirus SARS-CoV-2 (COVID19) Pandemic. Electron J Gen Med. 2020;17(4):em205. 2020. https://doi.org/10.29333/ejgm/7861

16. Bougherara $\mathrm{H}$, Benramache $\mathrm{S}$. The Effect of Climate and the Equator on the Total Coronavirus Cases of the Nine Countries from Africa. J Clin Exp Invest. 2020;11(3):em00747. https://doi.org/10.5799/jcei/8263

17. Zhao S, Gao D, Zhuang Z, Chong M, Cai Y, Ran J, et al. Estimating the serial interval of the novel coronavirus disease (COVID-19): A statistical analysis using the public data in Hong Kong from January 16 to February 15, 2020. medRxiv. 2020. https://doi.org/10.21203/rs.3.rs-18805/v1

18. Zhao S, Chen H. Modeling the epidemic dynamics and control of COVID-19 outbreak in China. Quantitative Biology. 2020:1-9. https://doi.org/10.1101/2020.02.27. 20028639

19. Layelmam M, Laaziz YA, Benchelha S, Diyer Y, Rarhibou S. Forecasting COVID-19 in Morocco. J Clin Exp Invest 2020. 2020;11(3):em00748. https://doi.org/10.5799/jcei/8264

20. Tuite AR, Fisman DN, Greer AL. Mathematical modelling of COVID-19 transmission and mitigation strategies in the population of Ontario, Canada. CMAJ. 2020. https://doi.org/10.1101/2020.03.24.20042705

21. UN. Department of Economic and Social Affairs Population Dynamics United Nations. Available at: https://population.un.org/wpp/ (Accessed: 17 April 2020).

22. World Population Review: Former USSR Countries by Population 2020: World Population Review.. Available at: https://worldpopulationreview.com/countries/formerussr-countries/ (Accessed: 17 April 2020).

23. WBD. World Bank Data: Europe \& Central Asia: The World Bank Group. Available at: https://data.worldbank.org/ region/europe-and-central-asia?view=chart (Accessed: 17 April 2020).

24. WATS. World Air Transport Statistics 2019: International Air Transport Associatio; 2020. Available at: https://www.iata. org/contentassets/a686ff624550453e8bf0c9b3f7f0ab26/w ats-2019-mediakit.pdf (Accessed: 17 April 2020).

25. Weber L. International Civil Aviation Organization: Kluwer Law International BV; 2017.

26. WHO. Laboratory testing for coronavirus disease 2019 (COVID-19) in suspected human cases: interim guidance, 2 March 2020. World Health Organization; 2020.

27. Pell B, Kuang Y, Viboud C, Chowell G. Using phenomenological models for forecasting the 2015 Ebola challenge. Epidemics. 2018;22:62-70. https://doi.org/ 10.1016/j.epidem.2016.11.002 PMid:27913131

28. Peng L, Yang W, Zhang D, Zhuge C, Hong L. Epidemic analysis of COVID-19 in China by dynamical modeling. arXiv preprint arXiv:200206563. 2020. https://doi.org/10.1101/ 2020.02.16.20023465

29. Hallauer W, Slemp W, Kapania R. Curve fitting freevibration time response for estimation of structural dynamic parameters. Experimental Techniques. 2010;34(1):26-33. https://doi.org/10.1111/j.1747-1567. 2008.00449.x 
30. Cheynet E. Generalized seir epidemic model (fitting and computation), 2020. Available at: https://wwwgithubcom/ ECheynet/SEIR

31. Flaxman S, Mishra S, Gandy A, Unwin H, Coupland H, Mellan $T$, et al. Report 13: Estimating the number of infections and the impact of non-pharmaceutical interventions on COVID19 in 11 European countries. 2020. https://doi.org/ 10.1038/s41586-020-2405-7 PMid:32512579
32. Bai Z, Gong Y, Tian X, Cao Y, Liu W, Li J. The Rapid Assessment and Early Warning Models for COVID-19. Virologica Sinica. 2020:1. https://doi.org/10.1007/s12250020-00219-0 PMCid:PMC7110270

33. Niazkar M, Niazkar H. COVID-19 Outbreak: Application of Multi-gene Genetic Programming to Country-based Prediction Models. Electron J Gen Med. 2020;17 (5):em247. https://doi.org/10.29333/ejgm/8232 


\section{APPENDIX 1}

\section{SPEIQRD Framework}

In the SPEIQRD framework where a country population of size, $\mathrm{N}$, is divided into seven subclasses such as $\mathrm{S}$, Susceptible population: these are the individuals who have never been exposed to the COVID-19 virus; $P$, Insusceptible population: this is a subpopulation of $\mathrm{S}$ which contains individuals who become insusceptible due to a protection; $\mathrm{E}$, Exposed population: asymptomatic individuals who have been in contact with COVID-19 agent but do not transmit the disease (in a latent period); I, Infected population: infected individuals can transmit the disease; Q, Isolated or quarantined population: this is a subpopulation of I which was isolated or quarantined due to being tested COVID-19 positive; R, Recovered population: a subpopulation of $Q$ individuals who have ceased being infectious; D, Removed (dead) population: a subpopulation of Q individuals dead due to COVID19 infection

The total population satisfies the equation $N=S(t)+P(t)+E(t)+I(t)+Q(t)+R(t)+D(t)$. We refer to a schematic illustration of the model in the figure which takes the following form Model 1 :

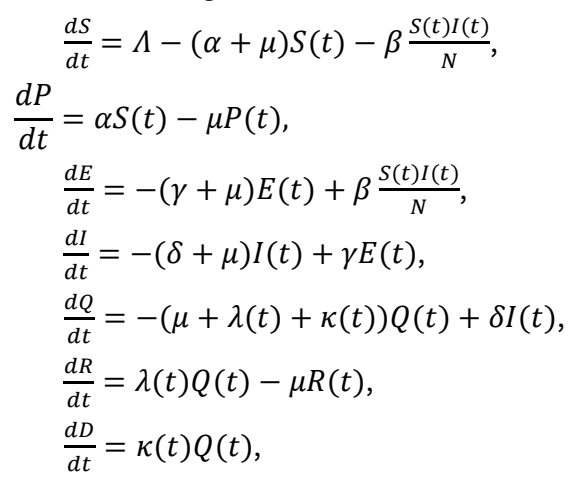

where $\frac{d L}{d t}$ models the rate of change in the subpopulation $L=(34 \mathrm{I}, \mathrm{Q}, \mathrm{R}, \mathrm{D})$ at day $\mathrm{t}, \Lambda$ is the rate at which individuals are born into the population $\alpha$ is the protection rate, $\mu$ is the natural death rate, $\beta$ is the per capita infection rate of an average susceptible provided that everyone else is infected, $\gamma$ and $\delta$ are the rates at which individuals leave the exposed and infectious classes, respectively. Moreover, $\lambda(t)$ and $\kappa(\mathrm{t})$ are the treatment and disease-related (COVID-19) death rate, respectively. Thus, $1 / \mu$ is the average life expectancy, $1 / \mathrm{N}$ gives the probability that a given contact is with an infectious individual. Further, $1 / \gamma$ and $1 / \delta$ give the average length of the latent and isolation (quarantine) periods, respectively. For the treatment and COVID-19 death rates we have used the following time-dependent functions: $\kappa(t)=\kappa_{1}{ }^{\star} \exp \left(-\kappa_{2}{ }^{*} t\right)$ and $\lambda(t)=\lambda 1 *(1-\exp (-\lambda 2 * t))$.

The parameters are listed below.

$\Lambda$ the rate at which individuals are born into the population

the protection rate

$\beta \quad$ the per capita transmission rate of the disease

$\lambda(t) \quad$ the treatment rate

$\kappa(\mathrm{t}) \quad$ the disease-related (COVID-19) death rate

$1 / \mu \quad$ the average life expectancy

$1 / \gamma \quad$ the average length of the latent period

$1 / \delta \quad$ the average length of the isolation (quarantine) period

Once we have a model the next question is to determine in terms of the given parameters so-called basic reproduction number, $\mathbf{R}_{\mathbf{0}}$, which serves as the threshold value. In epidemiology, $\mathbf{R}_{\mathbf{0}}$ is defined as the average number of new infectious cases produced by an infectious member of the host population. It is known that if $\mathbf{R}_{\mathbf{0}}>1$ then there will be an outbreak, otherwise, if $\mathbf{R}_{\mathbf{0}}<1$, the disease will die out. Thus, it is of utmost importance to find $\mathbf{R}_{\mathbf{0}}$. Note that the average length of infection is $\frac{1}{\delta+\mu}$ and recall that $\beta$ is the per capita infection rate. Further, the probability of an individual in exposed population becoming infectious before dying is $\frac{\gamma}{\gamma+\mu}$. Thus, in the case of $\alpha=0$, the basic reproduction number can be computed as:

$$
\mathbf{R}_{0}=\frac{\beta \gamma}{(\boldsymbol{\delta}+\mu)(\gamma+\mu)} .
$$

In the Covid-19 case, we take into account that the susceptible populations are decreasing not only due to infection and death but also becoming insusceptible due to protection measures such as lock-downs of cities and/or contact tracing of individuals. Therefore, $\alpha \neq 0$ in our model. In this case, following the study from (1) we compute the basic reproduction number as

$$
\mathbf{R}_{\mathbf{0}}=\frac{\boldsymbol{\beta} \gamma(\mathbf{1}-\boldsymbol{\alpha})^{t}}{(\boldsymbol{\delta}+\mu)(\gamma+\boldsymbol{\mu})}
$$


Supplement Table 1. Parameters are provided in the fitted model for each country as April 18, 2020

\begin{tabular}{ccccccccccccc}
\hline Country & $\boldsymbol{\alpha}$ & $\boldsymbol{\beta}$ & $\boldsymbol{\delta}$ & $\boldsymbol{\gamma}$ & $\boldsymbol{\lambda}_{\mathbf{1}}$ & $\boldsymbol{\lambda}_{\mathbf{2}}$ & $\boldsymbol{k}_{\mathbf{1}}$ & $\boldsymbol{k}_{\mathbf{2}}$ & $\boldsymbol{R}_{\mathbf{0}}$ \\
\hline Armenia & $4.28 \mathrm{E}-02$ & 1.1503 & 0.555 & 0.8514 & 0.4694 & 0.002 & 0.0024 & 1.8897 & 0.41 \\
\hline Azerbaijan & $1.52 \mathrm{E}-01$ & 1.4704 & 0.0766 & 0.2405 & 0.84 & 0.0019 & 0.2501 & 0.4101 & 0.061 \\
\hline Belarus & $5.07 \mathrm{E}-02$ & 1.1438 & 0.0015 & 0.3645 & 0.0289 & 0.0149 & 0.6999 & 0.1821 & 68.4017 \\
\hline Georgia & $3.17 \mathrm{E}-02$ & 1.0829 & 0.1722 & 0.0464 & 0.0233 & 0.1832 & 0.0009 & 0 & 1.6217 \\
\hline Kazakhstan & $1.60 \mathrm{E}-02$ & 1.127 & 0.6788 & 0.7002 & 0.4386 & 0.0019 & 0.0015 & 0.011 & 0.9305 \\
\hline Kyrgyzstan & $2.03 \mathrm{E}-02$ & 1.2222 & 0.7359 & 0.7339 & 0.4083 & 0.0028 & 0.2824 & 1.8208 & 0.8612 \\
\hline Moldova & $7.67 \mathrm{E}-02$ & 1.2833 & 0.163 & 0.3382 & 0.2922 & 0.0015 & 0.0131 & 0.0687 & 0.411 \\
\hline Russia & $1.16 \mathrm{E}-02$ & 1.0165 & 0.4133 & 0.403 & 0.0142 & 0.1174 & 0.0014 & 0.0001 & 1.5774 \\
\hline Uzbekistan & $8.92 \mathrm{E}-02$ & 1.0823 & 0.0731 & 0.2132 & 0.1213 & 0.0058 & 0.0026 & 0.0933 & 0.817 \\
\hline Ukraine & $3.55 \mathrm{E}-03$ & 1.1329 & 0.8715 & 1 & 0.0623 & 0.0049 & 0.005 & 0.0177 & 1.1683 \\
\hline Abbrea & & & &
\end{tabular}

Abbreviations: $\alpha$-alpha; $\beta$ - beta; $\gamma$-gamma; $\delta$-delta; $\Delta$ - kappa; $R_{0}$ - basic reproduction number.

Based on the mathematical modelling (Supplement Figure 1) it was estimated that among post-Soviet countries, Azerbaijan, Armenia, Moldova, Uzbekistan, Kyrgyzstan and Kazakhstan have managed to lower the reproduction number $\left(\mathrm{R}_{0}\right)<1(0.061,0.41$, $0.411,0.817,0.8612$ and 0.9305 , respectively). In the rest of the states, the reproduction numbers were quite close to 1 , not exceeding 1.63 (Russian Federation and Uzbekistan). Belarus had the largest and extreme reproduction number ( $\left.\mathrm{R}_{0}=68.4\right)$.

Supplement Table 2. Expected total number of COVID-19 confirmed cases in both best- and worst-case scenarios from the April 18,2020 until forthcoming 30 days and 60 days

\begin{tabular}{|c|c|c|c|c|}
\hline \multirow{2}{*}{ Country } & \multicolumn{2}{|c|}{ Expected total number of cases for 30 days } & \multicolumn{2}{|c|}{ Expected total number of cases for 60 days } \\
\hline & Best-scenario & Worst-scenario & Best-scenario & Worst-scenario \\
\hline Armenia & 1,243 & 1,329 & 1,243 & 1,329 \\
\hline Azerbaijan & 2,208 & 2,009 & 2,316 & 2,023 \\
\hline Belarus & 25,921 & 105,727 & 46,625 & 381,292 \\
\hline Georgia & 1,240 & 1,592 & 1,836 & 2,954 \\
\hline Kazakhstan & 2,674 & 3,794 & 2,691 & 4,002 \\
\hline Kyrgyzstan & 850 & 1,129 & 851 & 1,146 \\
\hline Moldova & 3,699 & 3,599 & 3,745 & 3,608 \\
\hline Russia & 551,725 & $1,009,069$ & $1,280,699$ & $5,342,998$ \\
\hline Uzbekistan & 4,547 & 5,642 & 5,217 & 6,462 \\
\hline Ukraine & 39,738 & 70,562 & 84,418 & 398,794 \\
\hline
\end{tabular}



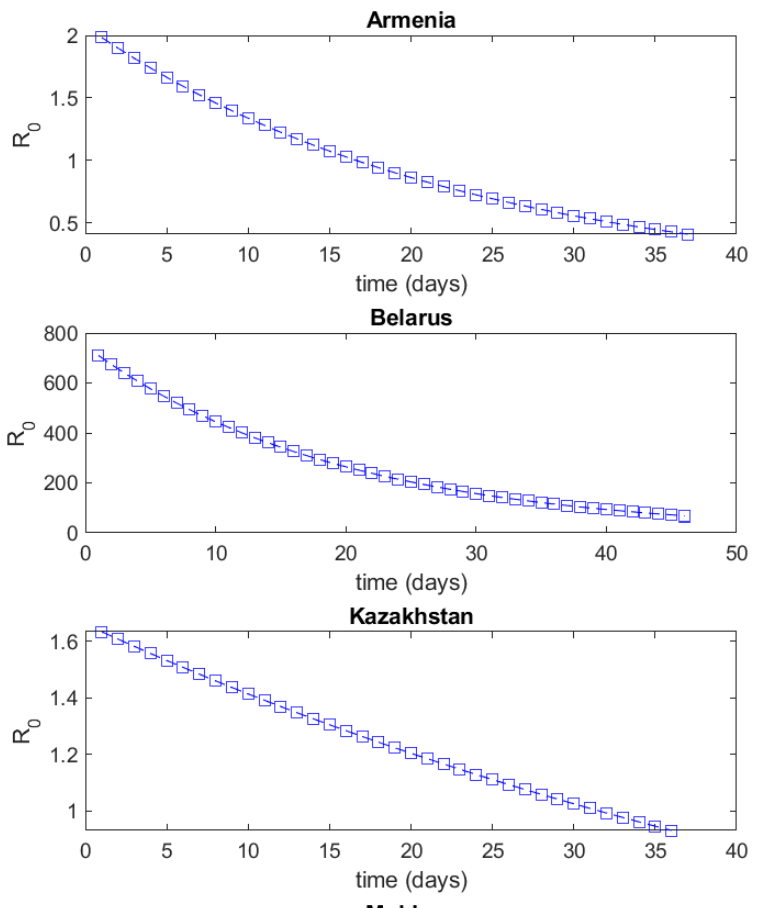

Moldova

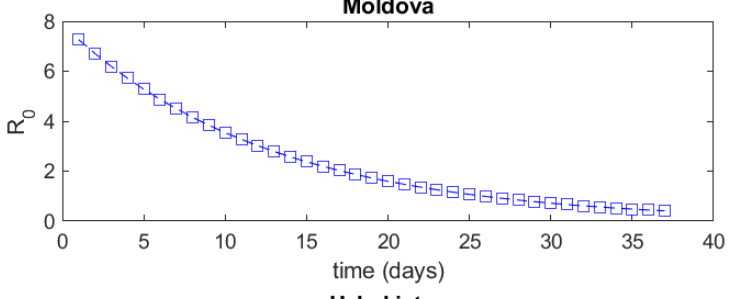

Uzbekistan

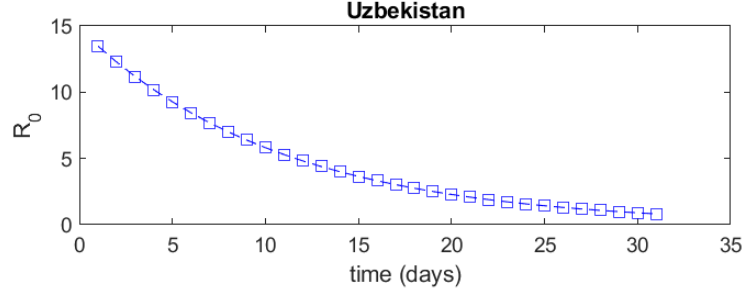

Azerbaijan

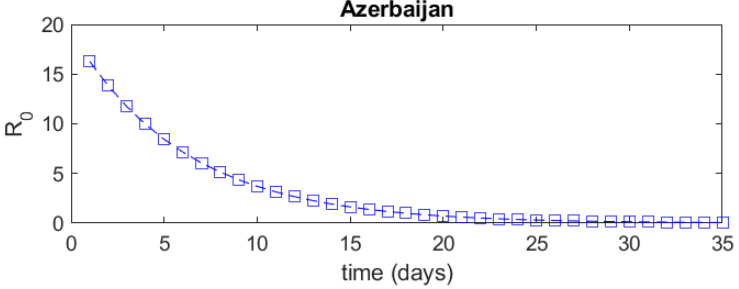

Georgia

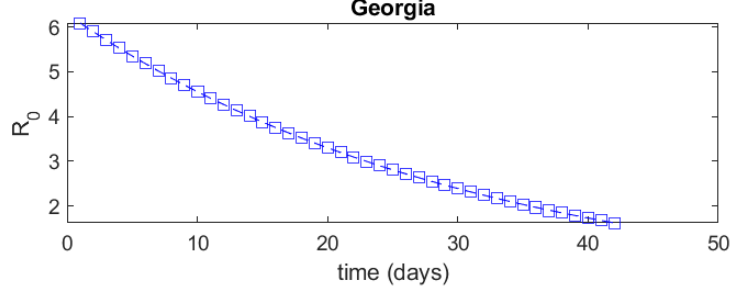

Kyrgyzstan

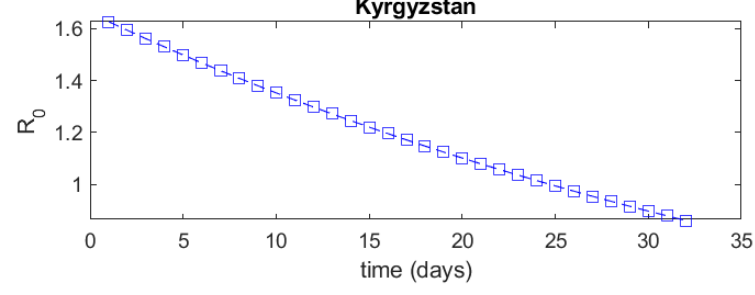

Russia

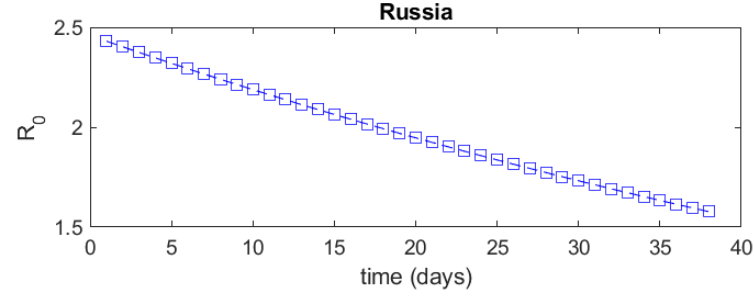

Ukraine

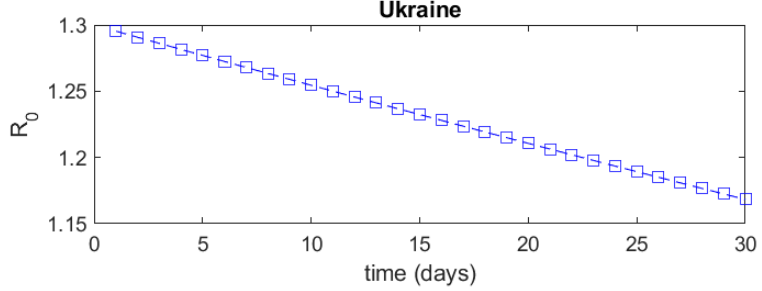

Supplement Figure 1. $R_{0}$ in modeling of COVID-19 outbreak for post-soviet countries Abbreviations: $R_{0}$ - reproduction number. 